$$
\begin{aligned}
\gamma & =\frac{k_{1} C_{B o}}{K_{L} a_{b} \sqrt{C_{A i}}} \\
\mu & =\text { viscosity of liquid } \\
\rho & =\text { density of liquid }
\end{aligned}
$$

〈Subscripts〉

$$
\begin{aligned}
& A, B, R, R_{1}, R_{2}, S=\text { components } \\
& i=\text { equilibrium value in liquid phase at gas-liquid } \\
& \text { interface } \\
& =\text { initial value } \\
& s \quad=\text { external surface of suspended solid catalyst }
\end{aligned}
$$

\section{Literature cited}

1) Albright, L. F.: Chem. Eng., Sept. 11, p. 197 (1967) and Oct. 9, p. 249 (1967)

2) Albright, L. F.: J. Am. Oil Chemists' Soc., 42, 250 (1965)

3) Allen, R. R. and A. A. Kiess: J. Am. Oil Chemists' Soc., 32, 400 (1955), 33, 355 (1956)

4) Armstrong, A. S.: Private communication
5) Brian, P. L. T. and H. B. Hales: A.I.Ch.E.J., 15, 419 (1969)

6) Calderbank, P. H. and M. B. Moo-Young: Chem. Eng. Sci., 16, 39 (1961)

7) Eldib, I. A. and L. F. Albright: Ind. Eng. Chem., 49, 825 (1957)

8) Elovich, S. Yu., G. M. Zhabrova, P. G. Krivenkova and T. D. Semenovskaya: J. Appl. Chemistry, U.S.S.R., 32, 188 (1959)

9) Harriott, P.: A.I.Ch.E.J., 8, 93 (1962)

10) Hashimoto, K., K. Muroyama and S. Nagata: $J$. Am. Oil Chemists' Soc., to be published

11) Kirk, R. E. and D. F. Othmer: "Encyclopedia of Chemical Technology", Vol. 6, p. 150, The Interscience Encyclopedia, Inc., New York (1951)

12) Nishitani, H., M. Morofuji, S. Gondo and K. Kusunoki: Preprint of the 8th General Symposium of the Soc. of Chem. Engineers, Japan, p. 60 (1969)

13) Satterfield, C. N.: "Mass Transfer in Heterogeneous Catalysis", p. 112-123, M.I.T. Press, Cambridge, Mass. (1970)

14) Wilke, C. R. and P. Chang: A.I.Ch.E.J., 1, 264 (1955)

15) Wisniak, J. and L. F. Albright: Ind. Eng. Chem., 53, $375(1961)$

\title{
KINETICS OF SULFUR DIOXIDE OXIDATION OVER ACTIVATED CARBON*
}

\author{
TSUTAO OTAKE, SETSUJI TONE, YOSHITSUGU YOKOTA** \\ AND KAZUO YOSHIMURA \\ Department of Chemical Engineering, Faculty of Engineering \\ Science, Osaka University, Toyonaka, Japan
}

\begin{abstract}
The rate of sulfur dioxide oxidation over activated carbon was measured in gaseous stream of sulfur dioxide-oxygen-nitrogen mixtures. It was found that catalyst fouling during the reaction was caused by sulfur trioxide formed on carbon. According to the LangmuirHinshelwood model, the over-all rate equation was derived on the basis of the mechanism where the rate-determining step is a surface reaction. The rate data were well correlated with the rate equation.
\end{abstract}

\section{Introduction}

The oxidation of sulfur dioxide over commercial vanadia catalyst has been studied by a number of investigators ${ }^{1 \sim 3)}$, but few kinetic studies of the oxidation of sulfur dioxide over activated carbon have been published. Siedlewski ${ }^{\text {})}$ reported the catalytic properties of activated carbon in the oxidation of sulfur dioxide to sulfur trioxide.

On the oxidation kinetics of sulfur dioxide over carbon, Yagi et al8). derived an over-all rate equation based on the assumption that the surface reac-

* Received on November 10, 1970

Presented at the Meeting of the 8th Symposium of the Soc. Chem. Engrs., Japan, November, 1969, Nagoya

** Toray Co., Ltd tion is the rate-controlling step. For the adsorption of sulfur dioxide in waste gases on atcivated carbons, Takahashi and $\mathrm{Seki}^{7}$ ) obtained an over-all rate equation by considering both phydical adsorption and oxidation of sulfur dioxide on the surface of the carbon. Recently, from rate measurements of the oxidation of sulfur dioxide in waste gases over carbon, Kiyoura et al..$^{5}$ found that the deactivation of activated carbon progressed with increasing amounts of sulfuric acid formed on the carbon.

The present investigation was undertaken to establish an over-all rate equation of the oxidation of sulfur dioxide over activated carbon. The rate of sulfur dioxide oxidation over carbon was measured in a gaseous stream of sulfur dioxide-nitrogen-oxygen mixtures. From the experimental data, it was found that the oxidation kinetics was surface reaction-controlling and that catalyst fouling was caused by the 


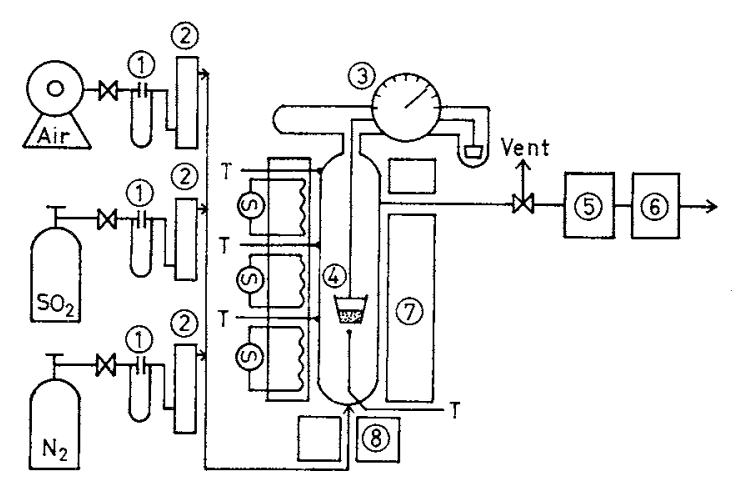

(1) orifice flowmeter (2) dryer (3) torsion balance (4) activated carbon (5) oxygen analyzer (6) sulfur dioxide analyzer (7) heating furnace (8) preheater

Fig. 1 Schematic diagram of the apparatus

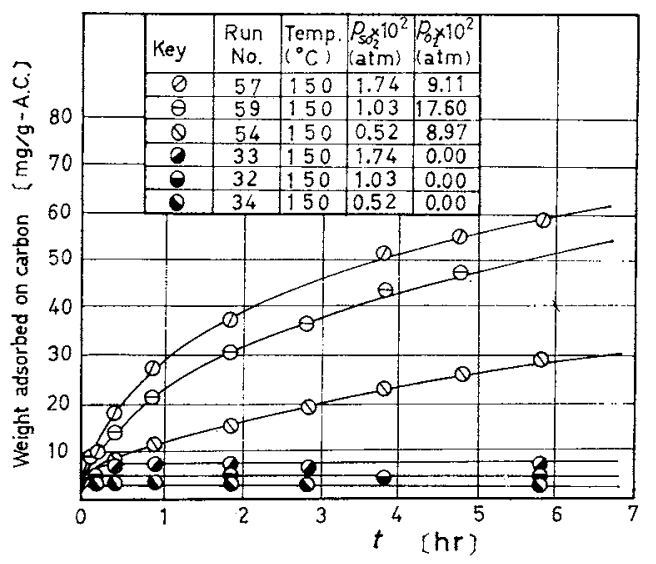

Fig. 2 Relation between weight adsorbed on carbon and time

Table 1 Physical properties of activated carbon (Shirasagi G)

particle size $=60 \sim 80$ Tyler mesh

specific surface area $=1.08 \times 10^{3} \mathrm{~m}^{2} / \mathrm{g}$

pore volume $=0.684 \mathrm{cc} / \mathrm{g}$

true density $=1.86 \mathrm{~g} / \mathrm{cc}$

particle density $=0.72 \mathrm{~g} / \mathrm{cc}$

\section{Table 2 Experimental conditions}

reactor tube diameter $=4 \mathrm{~cm}$

sample weight of activated carbon $=0.3 \mathrm{~g}$

gas flow rate $=1000 \mathrm{~m} l / \mathrm{min}$

fraction of sulfur dioxide $=0.2 \sim 3.0 \%$ vol.

fraction of oxygen $=4.0 \sim 16 \%$ vol.

$$
\text { (in reactant gas) }
$$

temperature $=50 \sim 150^{\circ} \mathrm{C}$

formation of sulfur trioxide on carbon during the oxidation.

The rate data were analyzed according to the Langmuir-Hinshelwood mechanism and an over-all rate equation for describing the surface reaction subject to catalyst fouling was represented. The experimental data were well correlated by the rate equation.

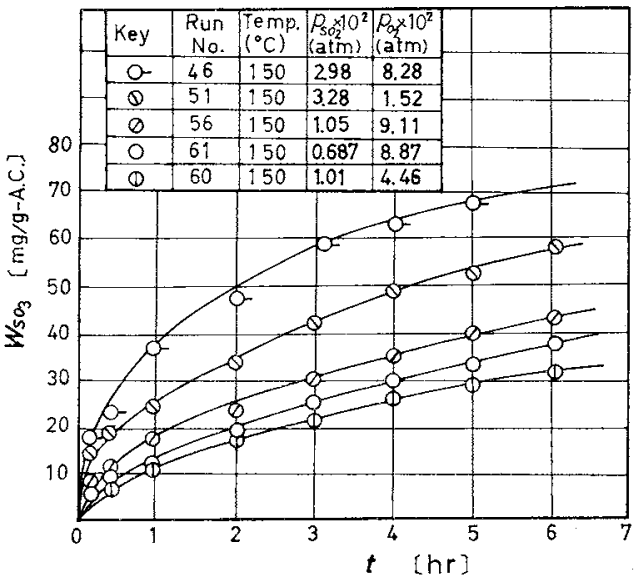

Fig. 3 Relation between the amount of sulfur trioxide formed on carbon and time

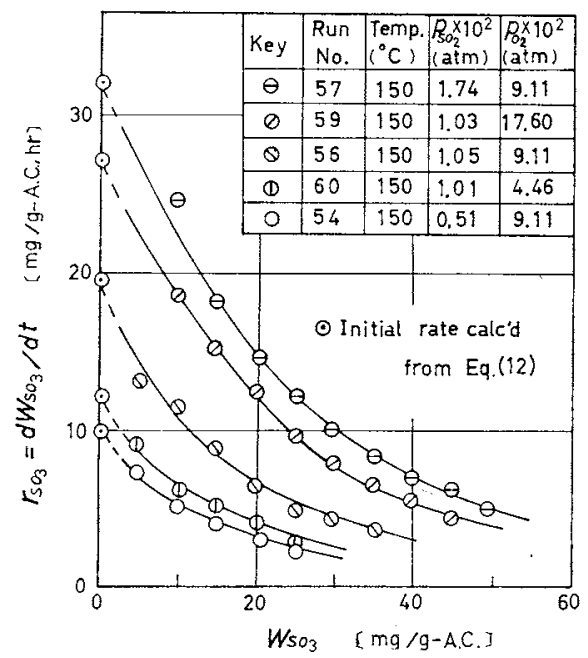

Fig. 4 Dependence of $r_{\mathrm{SO}_{3}}$ on $\mathrm{W}_{\mathrm{SO}_{3}}$

\section{Experimental}

\section{Experimental apparatus}

The schematic diagram of the apparatus is shown in Fig. 1. A stainless steel-wire basket to hold the carbon particles was suspended from a torsion balance into a reactor tube made of quartz. The reactor tube was surrounded by electric heaters consisting of three independently controlled heating blocks. For the gas analysis, an infrared sulfur dioxide analyzer (Hitachi-Horiba Co.) and a magnetic-type oxygen gas analyzer (Fuji Electric Co.) were connected to the reactor tube.

\section{Activated carbon}

Activated carbon used was Shirasagi G (Takeda Chemical Industries Co.). The physical properties of carbon particles, which were measured by the Brunauer-Emmett-Teller method and the helium-mercury penetration method, are shown in Table 1. At the beginning of each run, activated carbon was heated at $500^{\circ} \mathrm{C}$ in the nitrogen stream for one hour at a flow rate of $1000 \mathrm{ml} / \mathrm{min}$. The size of carbon particles was chosen in the range of 60-80 Tyler mesh so that 
diffusional effects could be neglected.

\section{Experimental procedure}

The experiments on adsorption and oxidation of sulfur dioxide over activated carbon were conducted as follows.

Oxidation-rate measurements: $0.3 \mathrm{~g}$ of activated carbon was placed in the reactor tube, which was preheated to a given temperature, and the nitrogen was continuously passed through. Then, the nitrogen flow was replaced by feed stream of a definite composition of sulfur dioxide-oxygen-nitrogen and the weight increase of activated carbon during the course of the reaction was measured by means of the torsion balance. The feed gases were prepared by adjusting the flow rates of sulfur dioxide, nitrogen and air. The air was purified by bubbling through concentrated sulfuric acid and passing through soda lime. The gas flow was operated at a rate of 1000 $\mathrm{m} l / \mathrm{min}$ for all cases. At the end of each run, the feed stream was cut off and the nitrogen stream was admitted to the reactor and continued until all the sulfur dioxide had been desorbed. The carbon, after removal of sulfur dioxide, was transferred to a beaker containing boiling water. The amount of sulfur trioxide formed on carbon was determined by titrating the resulting solution with $0.01 \mathrm{~N}$-barium chloride solution. All runs were conducted at the pressure of one atmosphere. The experimental conditions are summarized in Table 2.

Adsorption measurements: To study the adsorption rate of sulfur dioxide on carbon, the adsorbed amount was measured in a stream of sulfur dioxidenitrogen mixture by using the same apparatus. Similarly, the adsorption of oxygen was measured in a stream of oxygen-nitrogen mixture.

\section{Experimental Results}

Fig. 2 shows typical runs of the adsorption and the oxidation of sulfur dioxide over activated carbon. The adsorbed amounts of sulfur dioxide on carbon in the stream of sulfur dioxide-nitrogen mixtures reached equilibrium after about five minutes. The amounts of adsorbed gases on carbon in the stream of sulfur dioxide-oxygen-nitrogen mixtures increased with time owing to the accumulation of sulfur trioxide formed by the catalytic oxidation. After the desorption of sulfur dioxide by nitrogen flow was completed, the remaining adsorbate amount on carbon was equivalent to the amount of sulfur trioxide determined by chemical analysis. Sulfur trioxide was not detected by analysis in the effluent stream leaving the reactor tube. The desorption of sulfur trioxide was ignored. On the other hand, from the adsorption measurenents of oxygen on carbon in the stream of oxygen-nitrogen mixture, the change in weight of carbon was negligible.

The plots of the amount of sulfur trioxide formed on carbon against time are shown in Fig. 3. If the adsorption equilibrium is established instantaneously, the rate of oxidation becomes equal to the formation rate of sulfur trioxide. The rate of oxidation, accordingly, was obtained from graphical differentiation of the observde curves in Fig. 3. The rates are plotted against the amount of sulfur trioxide formed on carbon in Fig. 4. From Fig. 4, we conclude that the rate falls continuously with increasing amount of sulfur trioxide on carbon, and that deactivation of the catalyst occurs from the formation of strong bonds between carbon and sulfur trioxide.

\section{Interpretation and Correlation of Results}

\section{Expression for the reaction rate}

In the experimental study of the oxidation kinetics of sulfur dioxide over activated carbon, Yagi et al. ${ }^{8)}$ found that the forward rate was first order with respect to sulfur dioxide and 0.5 order to oxygen, and the reverse rate was first order with respect to sulfur trioxide formed on carbon. Kiyoura et al. ${ }^{5}$ obtained kinetic data of sulfur dioxide oxidation over carbon in a stream of waste gas and proposed an empirical rate equation involving the effect of catalyst fouling by the introduction of an activity factor expressed in terms of the amount of sulfuric acid on carbon.

For the sulfur dioxide oxidation subject to the activity decay of the carbon by the oxidation product, the authors will develop a rate expression according to the Langmuir-Hinshelwood model. The following assumptions are made.

1) Adsorption of sulfur dioxide is molecular, while that of oxygen is dissociative.

2) The adsorption equilibria are established instantaneously for both reactants and the surface reaction occurs between molecularly adsorbed sulfur dioxide and atomically adsorbed oxygen.

3) The sulfur trioxide desorption and the reverse surface reaction are ignored.

4) Catalyst fouling results from the depletion in the number of active sites by sulfur trioxide formation on carbon.

From the above assumptions (1)-(3), the mechanism may be written as follows.

$$
\begin{aligned}
& \mathrm{SO}_{2}+\sigma=\mathrm{SO}_{2}-\sigma \\
& \mathrm{O}_{2}+2 \sigma=2 \mathrm{O}-\sigma \\
& \mathrm{SO}_{2}-\sigma+\mathrm{O}-\sigma \nRightarrow \mathrm{SO}_{3}-\sigma+\sigma
\end{aligned}
$$

Here, $\sigma$ represents the site of active centers.

Since step (3) is assumed to be controlling, the reaction rate may be described by

$$
r_{\mathrm{SO}_{3}}=\frac{d W_{\mathrm{SO}_{3}}}{d t}=k \frac{C_{\mathrm{SO}_{2}} \cdot C_{\mathrm{o}}}{C_{t}}
$$

At adsorption equilibrium, the surface concentrations of sulfur dioxide and oxygen are given respectively by the expressions.

$$
C_{\mathrm{SO}_{2}}=K_{\mathrm{SO}_{2}} p_{\mathrm{SO}_{2}} C_{v} \quad(5), \quad C_{\mathrm{O}}=\sqrt{K_{\mathrm{O}_{2}} p_{\mathrm{O}_{2}}} \cdot C_{v}
$$

If one takes that $L_{\mathrm{SO}_{3}}$ is equal to the concentration of fouled active sites by sulfur trioxide formed on carbon, the total concentration of active centers is represented by 


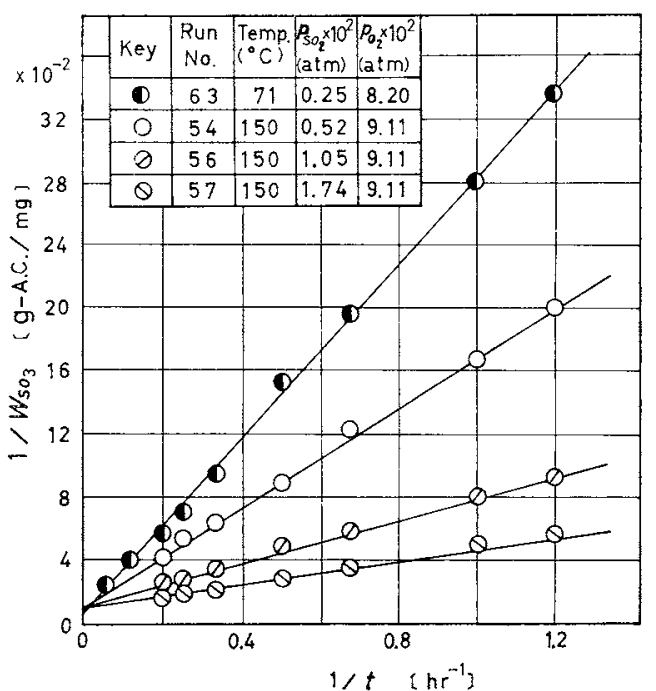

Fig. $51 / W_{\mathrm{SO}_{3}}$ vs. $1 / t$

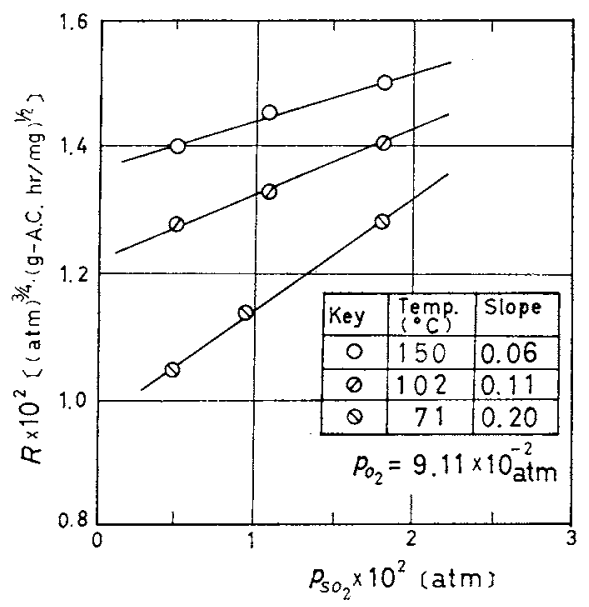

Fig. 6 Dependence of $R$ on $\mathrm{p}_{\mathrm{SO}_{2}}$

Table 3 The values of $\mathrm{W}_{\mathrm{SO}_{3}}^{\infty}$ evaluated

$\begin{array}{lllr}\left.\text { temperature [ }{ }^{\circ} \mathrm{C}\right] & 71 & 102 & 150 \\ W_{\mathrm{SO}_{3}}^{\infty}[\mathrm{mg} / \mathrm{g}-\mathrm{A} . \mathrm{C} .] & 95 & 100 & 90\end{array}$

$$
C_{t}=C_{\mathrm{SO}_{2}}+C_{0}+L_{\mathrm{SO}_{3}}+C_{v}
$$

On combining Eq.(4) with Eqs.(5)-(7) and eliminating $C_{v}$ from these equations, one obtains the rate equation in the following.

$$
r_{\mathrm{SO}_{3}}=\frac{K C_{t} \sqrt{K_{\mathrm{O}_{2}}} K_{\mathrm{SO}_{2}} / p_{\mathrm{O}_{2}}^{--} p_{\mathrm{SO}_{2}}}{\left(1+\sqrt{K_{\mathrm{O}_{2}} p_{\mathrm{O}_{2}}}+K_{\mathrm{SO}_{2}} p_{\left.\mathrm{SO}_{2}\right)^{2}}\right.} \cdot\left(1-\frac{L_{\mathrm{SO}_{3}}}{C_{t}}\right)^{2}
$$

If the concentration of fouled active sites is proportional to the amount of sulfur trioxide formed on carbon, $W_{\mathrm{SO}_{3}}$, the quotient $L_{\mathrm{SO}_{3}} / C_{i}$ may be replaced by $W_{\mathrm{SO}_{3}} / W_{\mathrm{SO}_{3}}^{\infty}$.

Rewriting Eq.(8), one obtains

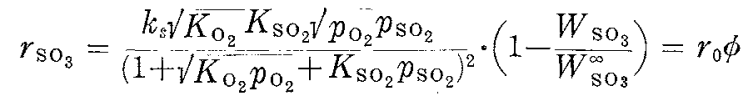

where

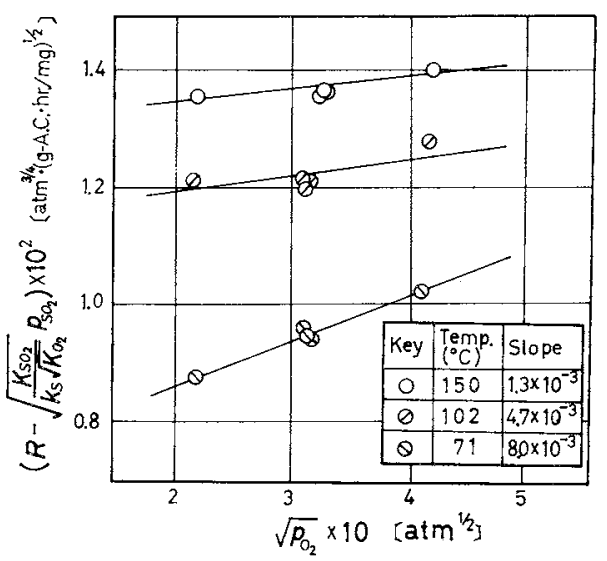

Fig. 7 Dependence of $\left(R-\sqrt{\frac{K_{\mathrm{SO}_{2}}}{k_{s} V K_{\mathrm{O}_{2}}}} \cdot p_{\mathrm{SO}_{2}}\right)$ on $\sqrt{p_{\mathrm{O}_{2}}}$

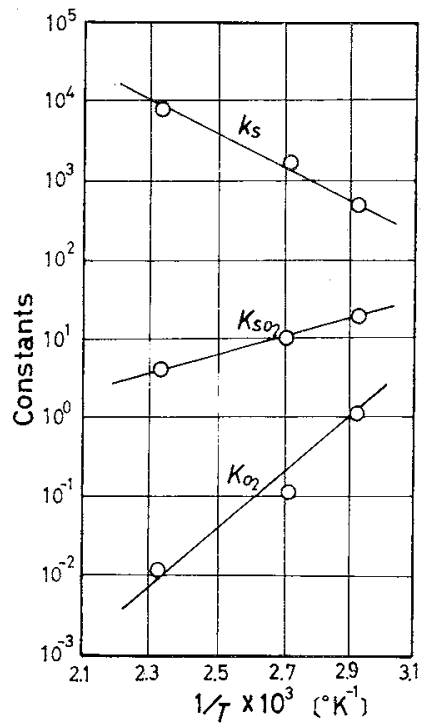

Fig. 8 Relation between constants and reciprocal absolute temperature

$$
\begin{aligned}
r_{0} & =\frac{k_{s} \sqrt{K_{\mathrm{O}_{2}}} K_{\mathrm{SO}_{2} \sqrt{2}} p_{\mathrm{O}_{2}} p_{\mathrm{SO}_{2}}}{\left(1+\sqrt{K_{\mathrm{O}_{2}}} p_{\mathrm{O}_{2}}+\bar{K}_{\mathrm{SO}_{2}} p_{\left.\mathrm{SO}_{2}\right)^{2}}{ }^{2}\right.}, \quad k_{s}=k C_{i} \\
\phi & =\left(1-W_{\mathrm{SO}_{3}} / W_{\mathrm{SO}_{3}}^{\infty}\right)^{2}
\end{aligned}
$$

As seen from Eq.(9), the over-all rate equation may be expressed by multiplying the initial rate, $r_{0}$, by an activity factor, $\phi$, which involves the effect on the catalyst deactivation of sulfur trioxide forming.

Determination of constants in the reaction rate equation

To apply Eq.(9) to the experimental data, Eq.(9) is integrated with time and can be rearranged to the form

$$
\frac{1}{W_{\mathrm{SO}_{3}}}=\frac{1}{r_{0} t}+\frac{1}{W_{\mathrm{SO}_{3}}^{\infty}}
$$

The plots of the reciprocal of $W_{\mathrm{SO}_{3}}$ against the reciprocal of time are shown in Fig. 5. The experimental data lie on straight lines given by Eq. (9) and the intercepts of the lines extrapolating to $1 / t=0$ give the values of $1 / W_{\mathrm{SO}_{3}}^{\infty}$ and the slopes of lines yield 
the valus of $1 / r_{0}$. The values of $W_{\mathrm{SO} \text { s }}^{\infty}$ evaluated at $71^{\circ}, 102^{\circ}$ and $150^{\circ} \mathrm{C}$ are tabulated in Table 3 .

The initial rate of reaction given by Eq.(10) is rearranged in the following.

$$
\begin{aligned}
R & =\sqrt{\frac{p_{\mathrm{SO}_{2}} \sqrt{p_{\mathrm{O}_{2}}}}{r_{0}}} \\
& =\frac{1}{\sqrt{k_{s} K_{\mathrm{SO}_{2}} \sqrt{K_{\mathrm{O}_{2}}}}}+\sqrt{\frac{K_{\mathrm{SO}_{2}}}{k_{s} \sqrt{K_{\mathrm{O}_{2}}}}} \cdot p_{\mathrm{SO}_{2}}+\sqrt{\frac{\sqrt{K_{\mathrm{O}_{2}}}}{k_{s} K_{\mathrm{SO}_{2}}}} \cdot \sqrt{p_{\mathrm{O}_{2}}}
\end{aligned}
$$

Plots of the values of $R$ against $p_{\mathrm{SO}_{2}}$ are shown in Fig. 6. The values of $\left(R-\sqrt{\frac{K_{\mathrm{SO}_{2}}}{k_{s} \sqrt{K_{\mathrm{O}_{2}}}}} \cdot p_{\mathrm{SO}_{2}}\right)$ against $\sqrt{p_{\mathrm{O}_{2}}}$ are plotted in Fig. 7. They show that the experimental data in conformity with the rate equation derived on the basis of the mechanism where the surface reaction is the controlling step. The intercepts and the slopes of the lines in Figs. 6 and 7 give the reaction rate constant and associated adsorption equilibrium constants. These constants are plotted in Fig. 8. These plots can be expressed by the following equations as functions of the reciprocal absolute temperature.

$$
\ln k_{s}=6.800-10,700 / R T
$$

and

$$
\begin{aligned}
& \ln K_{\mathrm{SO}_{2}}=0.260+6,600 / R T \\
& \ln K_{\mathrm{O}_{2}}=-3.200+17,000 / R T
\end{aligned}
$$

The apparent activation energy of the reaction is $10.70 \mathrm{kcal} / \mathrm{mol}$ and the heat of adsorption of sulfur dioxide is $6.60 \mathrm{kcal} / \mathrm{mol}$. The latter is nearly equal to the latent heat of evaporation of sulfur dioxide. Therefore, the adsorption of sulfur dioxide on carbon may be considered as physical.

On the other hand, the heat of adsorption of oxygen on carbon is $17.00 \mathrm{kcal} / \mathrm{mol}$, which is a value near to the heat of chemisorption reported by other investigators $^{4)}$. Consequently, it is interpreted that the surface reaction proceeds between physically adsorbed sulfur dioxide and chemisorbed atomic oxygen on carbon.

\section{Conclusion}

Measurements of the rate of sulfur dioxide oxidation over activated carbon were made under various conditions. Effect of the partial pressures of sulfur dioxide and oxygen of the rate was examined. Under the conditions investigated, it was found that the oxidation suffers the effect of catalyst deactivation due to sulfur trioxide formed on carbon. To analyze the rate data, a reaction rate model was built up according to the Langmuir-Hinshelwood mechanism with the assump- tion that the rate-determining step is the surface reaction involving physically adsorbed sulfur dioxide and chemisorbed atomic oxygen. The over-all rate equation for the oxidation of sulfur dioxide subject to catalyst fouling was established, and by comparing the rate equation with the experimental data, the rate parameters were evaluated and correlated with temperature.

\section{Nomenclature}

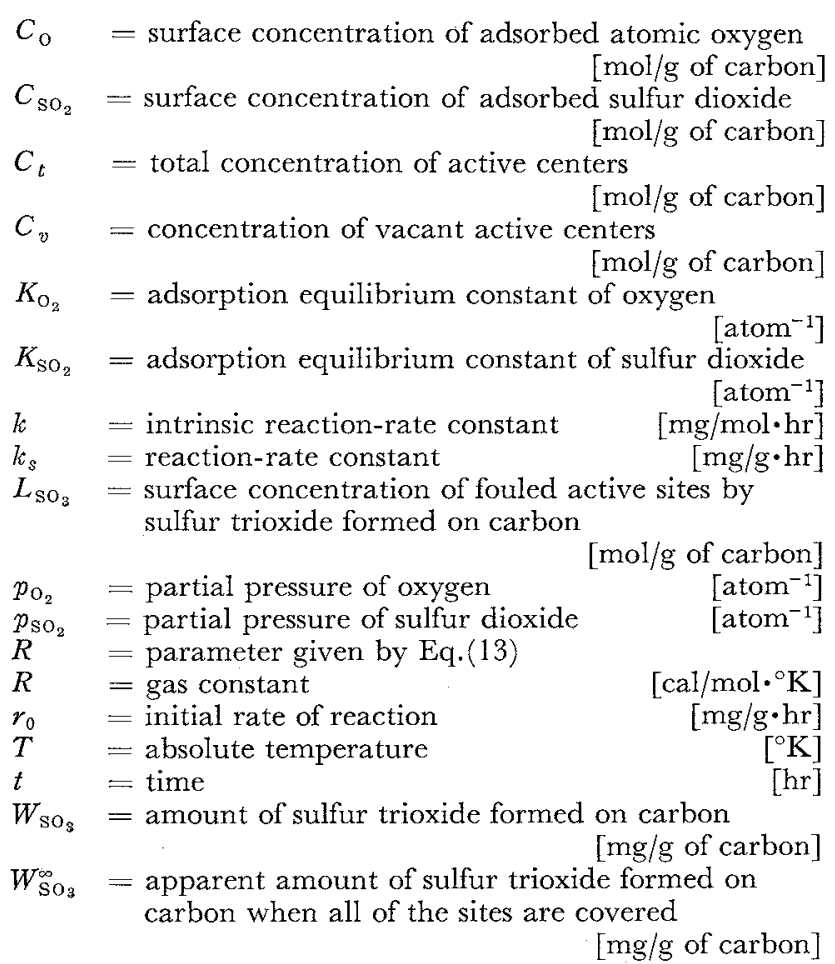

\section{Literature cited}

1) Davidson, B. and G. Thodos: A.I.Ch.E. J. 10, 568 (1964)

2) Goldman, M., L. M. Canigar and R. B. Beckmann: J. Appl. Chem., 7, 278 (1957)

3) Hara, H., A. Adachi and N. Kurata: Kogyo Kagaku Zasshi, (J. Chem. Soc., Japan./Ind. Chem. Section), 63, 56 (1960)

4) Kays, F. G. and M.J. Marshall: J. Am. Chem. Soc., 49, 156 (1927)

5) Kiyoura, R., H. Kuronuma and K. Kyono: Preprint of the 22th Annual Meeting of Chem. Soc. Japan, part 4, p. 820, April, 1969, Tokyo

6) Siedlewski, J.: Int. Chem. Eng., 4, 33 (1967)

7) Takahashi, R. and M. Seki: Preprint of the 6th Symposium of the Soc. Chem. Engrs., Japan, p. 140, November, 1967, Nagoya.

8) Yagi, S., E. Oshima and Y. Sudo: Preprint of the 4th Symposium on Reaction Eng., the Soc. Chem. Engrs., Japan, November, 1964, Osaka 